\title{
The study of dynamic change of enzymatic activities in Chrysanthemum field with different coating material
}

\author{
wei-sheng Shi ${ }^{\text {a }}$, yang LI , hai-ming Liu, zheng Peng and fu-jie Zhang \\ Faculty of Modern Agriculture Engineering, Journal of Kunming University of Science and \\ Technology, Kunming 650500,China \\ a shiweisheng888@sina.com
}

Keywords: coated material ; activities of enzymatic; dynamic change;

Abstract. the effect of dynamic change activities of enzymatic in Chrysanthemum field with different coating material was studied With three kinds of coated compound fertilizer as raw materials. Results show that the soil enzymatic activities of catalase, sucrase and urease increased first and then decreased at different Chrysanthemum growth stage; By comparing the Coated compound fertilizer of coated materials of Idesia polycarpavar.vestita with $\mathrm{CK}$, we realized the quantity of soil catalase increased $0.26 \mathrm{~mol} / \mathrm{L}$ 、 that of soil sucrase increased $1.72 \mathrm{mg} / \mathrm{g}$, that of soil urease increased 0.08 $\mathrm{mg} / \mathrm{g}$ and that of the Stalk weight increased $2.0 \mathrm{~g} / \mathrm{strip}$. That was beneficial to the improvement of soil enzyme activity of coated compound fertilizer as raw materials oil of Idesia polycarpa var.vestita.

\section{Introduction}

Controlled release fertilizer is to be considered as one of the most effective way to improve the utilization ratio of fertilizer. Its nitrogen use efficiency can reach to $30 \%--35 \%$ in the china countries, hence fertilization technology has become a difficulty[1]. The nutrient's absorption and utilization ,transformation, release and fixed by Chrysanthemum from the soil is closely related to the amount of soil enzyme. Mantens' [2,3] research shows that soil fertility conditions is closely related to the amount of soil enzyme, its enzyme activity can be used as an important index of soil fertility level.

Currently there exists quite much research result [4,5], which suggests that many scholars have done enough study about the effect of activities of enzymatic in Chrysanthemum field with different coating material, but rarely have anyone studied the growth management way of Chrysanthemum or the technical measures. Therefore, how to fully utilize fertilizer improving production and how to know of activities of enzymatic in soil with different coating material become the key problems of this study.

This paper, through the study of applying different fertilizer improving production and the study of dynamic change activities of enzymatic in Chrysanthemum field with different coating material, helps setting up the basis for the development and utilization of coated materials in terms of the environmental effect of soil enzyme activity of coated materials.

\section{Material and method}

\section{Material}

Idesia polycarpa var.vestita oil: produced by Wenshan Yunnan Oil limited company, acid value is 2.61, viscosity is $256 \mathrm{mPas}$ [6];Talcum powder: produced by Yunnan Yunhua company; Coated compound fertilizer as raw materials of the Idesia polycarpa var.vestita oil: Idesia polycarpa var.vestita oil and talcum powder mixed at a certain ratio.; Coated compound fertilizer as raw materials of the tung oil: tung oil and talcum powder mixed at a certain ratio; Coated compound fertilizer as raw materials of the Rosin Glycerin Ester: the Rosin Glycerin Ester and talcum powder mixed at a certain ratio.

The Coated compound fertilizer of coated materials : its coating coverage is $6.1 \%$,the total content of effective part is $35 \%, \mathrm{~N}: \mathrm{P}_{2} \mathrm{O}_{5}: \mathrm{K}_{2} 0=13: 11: 7$, controlled release period is 4 months. 


\section{Method \\ Observation project}

The investigation of agronomic characters includes plant height, Stalk weight and other main agronomic characters.Five plants were randomly selected in each line, averaging the average.

\section{The determination of soil enzyme activity}

They were determined in different growth periods. Sodium dihydrogen phosphate colorimetric method was used to determine the sucrase, permanganate titration was used to determine the Soil catalase and phenol a sodium hypochlorite colorimetric method was used to determine the urease [7].

\section{Test set}

Test uses Random permutation method and repeat 3 times,the experimental area include six lines, the length of each line is four $\mathrm{m}$ and the area is $2 \mathrm{~m}^{2}$. The soil physical-chemical properties: $\mathrm{pH}$ value 5.64 , organic matter $11.7 \mathrm{~g} / \mathrm{kg}$, total nitrogen $1.28 \mathrm{~g} / \mathrm{kg}$, alkali-hydro nitrogen $86.8 \mathrm{mg} / \mathrm{kg}$, rapid-available phosphorus $14.0 \mathrm{mg} / \mathrm{kg}$, rapidly-available potassium $174 \mathrm{mg} / \mathrm{kg}$.

Aapplying coated fertilizer as basal fertilizers, $\mathrm{N}: \mathrm{P}_{2} \mathrm{O}_{5}: \mathrm{K}_{2} \mathrm{O}=13: 11: 7$, phosphate,potash fertilizer supplement from potassium dihydrogen phosphate (chemical pure) and potassium sulfate (chemical pure). Fertilizer test start on five 20th,2015. Surveying and testing Agronomic traits of sugarcane on Eight 20th, 2015. It should be consistent with cultivation and management measures ,such as cultivation, irrigation-drainage and in kunming City, Yunnan Province, P.R.China.

Table 1. Experimental treatment

\begin{tabular}{llll}
\hline $\begin{array}{l}\text { Treatme } \\
\mathrm{nt}\end{array}$ & commodity & $\begin{array}{l}\mathrm{N}: \mathrm{P}_{2} \mathrm{O}_{5}: \\
\mathrm{K}_{2} \mathrm{O}\end{array}$ & $\begin{array}{l}\text { Dosage }(\mathrm{kg} / \\
\left.\mathrm{hm}^{2}\right)\end{array}$ \\
\hline 1 & the tung oil & $13: 11: 7$ & 1050 \\
2 & the Rosin Glycerin Ester & $13: 11: 7$ & 1050 \\
3 & Idesia polycarpavar.vestita & $13: 11: 7$ & 1050 \\
4 & Common compound & $13: 11: 7$ & 1050 \\
& fertilizer(CK) & & \\
\hline
\end{tabular}

\section{Data processing}

The data are the average of 5 times repetion and we are using the Excel3.0 to analyse.

\section{Result and analysis}

The effect of different treatments on main agronomic characters of Chrysanthemum

It is shown in table 2 that the plant height: Test one--compared with $\mathrm{CK}$, the plant height increased $2.6 \mathrm{~cm}$. Test two--compared with $\mathrm{CK}$, they increased $1.2 \mathrm{~cm}$. Test three--compared with $\mathrm{CK}$, the plant height increased $1.8 \mathrm{~cm}$. The lowest range of increase comes from test three. The growth rate in test one is highest. Based on the Chrysanthemum obtain same nutrient content - the choice of coated fertilizer does not much affect the plant height of Chrysanthemum.

Analysis of the number of Stalk weight: Test one--compared with CK, the number of Stalk weight increased $0.1 \mathrm{~g} / \mathrm{strip}$. Test two--compared with CK, the number of Stalk weight increased $1.1 \mathrm{~g} / \mathrm{strip}$. Test three --compared with CK, the number of Stalk weight increased $2.0 \mathrm{~g} / \mathrm{strip}$, among them, the growth rate in test three is highest, this result indicate that the controlled-release period of the coated compound fertilizer of coated materials of Idesia polycarpavar.vestita is four months, this just meet the nutrient needs of the Chrysanthemum during Stem elongation stage to promote the growth. the Stalk weight increase rate of test three is highest. 
Table 2.The effect of different treatments on main agronomic characters of sugarcane

\begin{tabular}{llll}
\hline Treatment & $\begin{array}{l}\text { Stalk diameter } \\
(\mathrm{cm})\end{array}$ & $\begin{array}{l}\text { Plant height } \\
(\mathrm{cm})\end{array}$ & $\begin{array}{l}\text { Stalk weight } \\
(\mathrm{g} / \mathrm{strip})\end{array}$ \\
\hline 1 & 0.64 & 29.3 & 12.3 \\
2 & 0.68 & 27.9 & 13.3 \\
3 & 0.71 & 28.5 & 14.2 \\
$\mathrm{CK}$ & 0.42 & 26.7 & 12.2 \\
\hline
\end{tabular}

\section{The activity of soil catalase on different treatment}

It is shown in chart 1 that the soil enzymatic activities of catalase increased first and then decreased with the different Chrysanthemum growth stage in different treatment. With different treatment and the activities of catalase will create peak in Chrysanthemum stem elongation stage.

Analysis of the data: other conditions being the same,the Test three compared with CK, the quantity of soil catalase increased $0.26 \mathrm{~mol} / \mathrm{L}$ in the Chrysanthemum stem elongation stage. Test one compared with test four, the quantity of soil catalase increased $0.16 \mathrm{~mol} / \mathrm{L}$, it is shown that the coated materials began to induce the activity of soil catalase. Test two compared with test four, the quantity of soil catalase decreased $0.08 \mathrm{~mol} / \mathrm{L}$, it is show that the coated compound fertilizer as raw materials of the Rosin Glycerin Ester have possible to induce the soil enzymatic activities of catalase .So that was beneficial to increase the quantity of soil catalase of coated compound fertilizer as raw materials oil of Idesia polycarpa var.vestita.

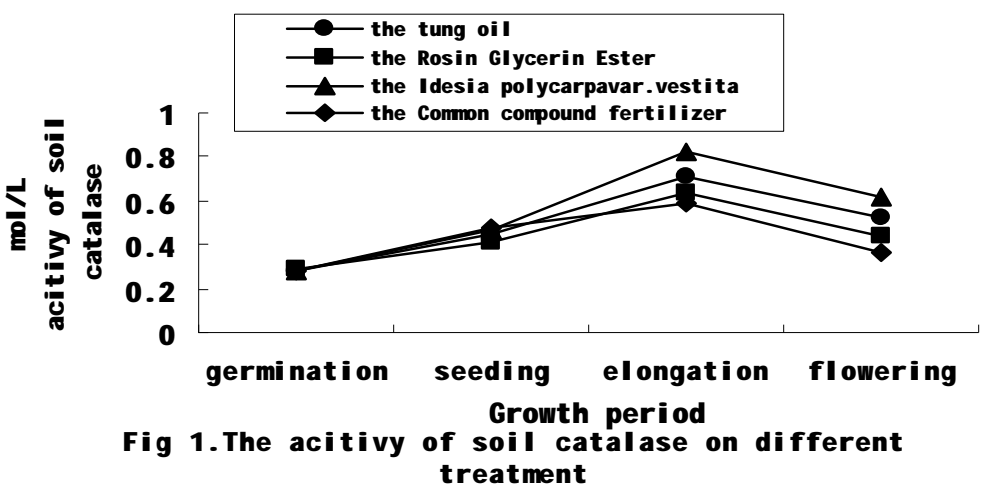

\section{The activity of soil sucrase on different treatment}

It is shown in chart 2 that the soil enzymatic activities of sucrase increased first and then decreased at different Chrysanthemum growth stages. With different treatment,the activities of sucrase will create peak in the Chrysanthemum stem elongation stage, the peak of CK appears in the Chrysanthemum Seedling stage and the peak of the coated compound fertilizer appear in the stem elongation stage.

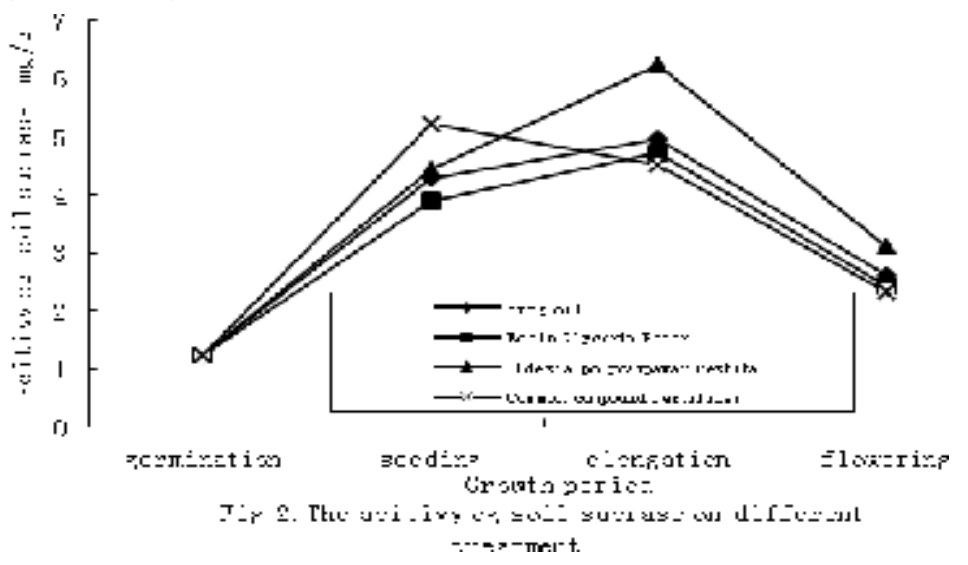

Analysis of the data: Test one three compared with CK, the quantity of soil sucrase increased $1.72 \mathrm{mg} / \mathrm{g}$ in the Chrysanthemum stem elongation stage; Test one compared with test four, the quantity of soil sucrase increased $0.2 \mathrm{mg} / \mathrm{g}$; Test two with test four, the quantity of soil sucrase 
increased $0.2 \mathrm{mg} / \mathrm{g}$. In such an environment, the coated compound fertilizer as raw materials of the Idesia polycarpa var.vestita oil can induce the soil enzymatic activities of sucrase more effectively than the coated compound fertilizer as raw materials of the tung oil and the Rosin Glycerin Ester.

The highest quantity of soil sucrase is $6.24 \mathrm{mg} / \mathrm{g}$ from test three.It is show that the coated compound fertilizer as raw materials of the Idesia polycarpa var.vestita oil was beneficial to the improvement of soil enzyme activity of sucrase.

\section{The activity of soil sucrase on different treatment}

It is shown in chart 3 that the soil enzymatic activities of urease increased first and then decreased with the different Chrysanthemum growth stage. The activities of urease will create peak in Chrysanthemum stem elongation stage and the peak of CK appears in Chrysanthemum Seedling stage. the coated compound fertilizer was beneficial to the improvement of soil enzyme activity of urease.

Analysis of the data: the Test three compared with CK, the quantity of soil urease increased $0.08 \mathrm{mg} / \mathrm{g}$ in the Chrysanthemum stem elongation stage; Test one compared with test four, the quantity of soil urease increased $0.03 \mathrm{mg} / \mathrm{g}$; Test two compared with test four, the quantity of soil urease increased $0 \mathrm{mg} / \mathrm{g}$. In such an environment,test three compared with $\mathrm{CK}$, the quantity of soil urease increased $0.04 \mathrm{mg} / \mathrm{g}$ in Chrysanthemum Seedling stage; Test one compared with test four, the quantity of soil urease increased $0.01 \mathrm{mg} / \mathrm{g}$; Test two compared with test four, the quantity of soil urease decreased $0.03 \mathrm{mg} / \mathrm{g}$.It is show that the coated compound fertilizer as raw materials of the Idesia polycarpa var.vestita oil was beneficial to the improvement of soil enzyme activity of urease.

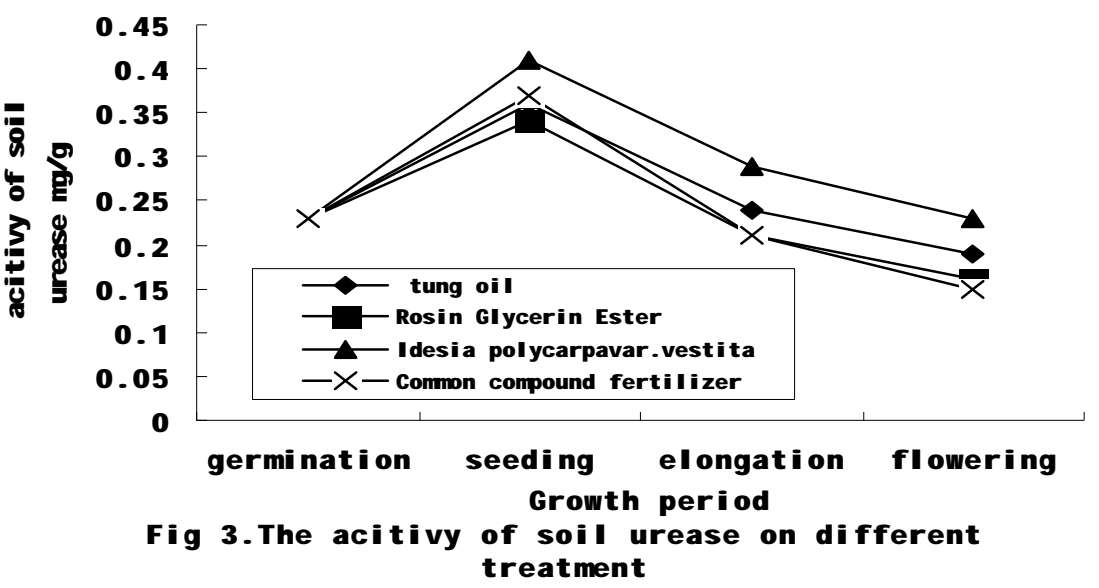

\section{Conclusion}

1) Compared with CK, the coated compound fertilizer as raw materials of the Idesia polycarpa var.vestita oil. has brought about a increase of $2.0 \mathrm{~g} / \mathrm{strip}$ of Stalk weight to production and it best improves Stalk weight percentage among other methods.

2) Compared with CK, Test one and Test two suggest that the quantity of soil urease decreased, the soil catalase and sucrase increased less, which indicates that the coated compound fertilizer as raw materials of the tung oil and the Rosin Glycerin Ester are possible to induce the soil enzymatic activities of catalase, sucrase and urease.

3 ) Compared with $\mathrm{CK}$, the Coated compound fertilizer of coated materials of Idesia polycarpavar.vestita has made the quantity of soil catalase increased $0.26 \mathrm{~mol} / \mathrm{L}$ 、 that of soil sucrase increased $1.72 \mathrm{mg} / \mathrm{g}$ 、 that of soil urease increased $0.08 \mathrm{mg} / \mathrm{g}$. That was beneficial to the improvement of soil enzyme activity of coated compound fertilizer as raw materials oil of Idesia polycarpa var.vestita.

\section{References}

[1] Xiaolin Fan, Fang Liu, Zhaoyuan Liao, eta1.The status and outlook for the study of controlled release fertilizers in China[J].Plant Nutrition and Fertilizer Science,2009,15(2):463-473.in Chinese. 
[2] William P M.Reacted layer technology for controlled release[J].Science,1990(3):1-8.

[3]Mantens D A,Johanson J B,Frakenberger W T.Production and persistence of soil enzymes with repeated additions of oaganic residues[J].Soil Sci,1992,153:59-61.

[4] Zheng-qing Gao, Yue-bin ZHang,etal.Developmental Progress of Xylitol Production by Canesugar Bagasse[J].Sugar Crops of China,2009,(3):54-64.in Chinese.

[5] H.W. Tan,L.Q. Zhou,R.L.Xie.Study on the Sulfur Nutrition of the Sugarcane and Balance of Sulfur in Soil for Sugarcane Planting Areas[J].Journal of Environmental Science and Engineering.2010,4(9):40-43.

[6] Wei-sheng Shi,Ji-lin Liu,qian Lei,etal. A Study on the Contral Effect of Idesia polycarpa var.vestita.Dregs on Monochoria vaginalis[J].Journal of Northwest Forestry Universit.2005,(20)4:119-121.in Chinese.

[7] Burns R G.Soil Enzymes[M].Chelsea,USA:Lewis Publishers,1994.93—97. 